\title{
Deciding Novelty of Submitted Manuscript
}

\author{
A. V. Adedayo ${ }^{1,2}$ \\ ${ }^{1}$ Department of Materials Science and Engineering, Obafemi Awolowo University, Ile-Ife, Nigeria \\ ${ }^{2}$ Department of Metallurgical Engineering, Kwara State Polytechnic, Ilorin, Nigeria
}

\section{Email address:}

a.v.adedayo@gmail.com

\section{To cite this article:}

A. V. Adedayo. Deciding Novelty of Submitted Manuscript. International Journal of Science, Technology and Society.

Vol. 3, No. 4, 2015, pp. 240-243. doi: 10.11648/j.ijsts.20150304.25

\begin{abstract}
The paper developed a framework for deciding the novelty of submitted manuscripts. The importance of novelty and objective decision of the novelty of submitted manuscripts is identified. A brief exposition on the meaning of novelty is presented and used as basis to form mathematical expressions to quantify the novelty of submitted manuscripts. The developed framework will be found more useful in objective decision of the novelty of submitted manuscripts as opposed to the current frustrating subjective methodology adopted by editors and reviewers world over.
\end{abstract}

Keywords: Manuscript Evaluation, Creativity, Newness, Interesting

\section{Introduction}

The significant feature of scientific communications which distinguishes them from other technical reports is the comprehensive independent review they undergo before publication. The review process involves the assessment and appraisal of a manuscript for the purpose of considering its suitability for publication. One of the important considerations when deciding acceptability of submitted manuscripts in scientific communications is novelty of the submitted manuscript. The importance of this issue becomes obvious right from the editorial review stage of submitted manuscripts when editors decide on the suitability of submitted manuscripts for publication. While some journal publishers believe that no manuscript should be rejected only on the basis of lack of novelty (Sciencedomain, 2015), however, in many other journal publications, novelty of the subject discussed in a manuscript is considered very vital (Benos et al., 2007; Brown, 2006). Oftentimes, a reject decision of submitted manuscript has been based on lack of novelty, while editors do not provide reference to confirm lack of novelty. Most of the time, the decision of a journal to publish a manuscript has been dominated by the opinion of the editor/reviewer as regards what they perceive as the novelty value of the manuscript. This judgment is subjective and most of the times leads to decisions which are frustrating (Sciencedomain, 2015). As a result, there has been significant clamour of biases in peer review process in academic publishing, especially where important innovations and findings, conflict with current beliefs (Armstrong, 1997). Various studies have been carried out to evaluate the empirical evidence of biases in the peer review process. While there is considerable opinion by many authors that the present method is crude, and provides an escape route for editors to justify a deliberate hateful reject decision; however, there are studies that suggest that biases in peer review are insignificant. In the studies carried out by van Rooyen et al., (1998) and Schroter et al., (2006); it was found out that blinding and unmasking made no significant difference to review quality, however, the result of the study by Fishers et al, (1994) suggest that blinded reviewers may provide more unbiased reviews and that non-blinded reviewers may be affected by various types of biases. Lee et al., (2012) identified that the evidence for bias against interdisciplinary research is mixed, as is the evidence for bias against female authors and authors living in non-English-speaking countries. However, they believe there is no empirical evidence to buttress or belie such worries of bias in peer evaluations as a function of author nationality; prestige of institutional affiliation and reviewer nationality.

The study by Jefferson et al., (2006) suggested that little empirical evidence is available to support the use of editorial peer review as a mechanism to ensure quality. The process of peer review is considered to be steeped in tradition. In the realm of innovation and science, tradition operates on a dayto-day basis; and the current system of peer review is not perfect! (Benos et al., 2007).

Also, there is the concern about; whether reviewers 
adequately grasp the subject of novelty when it comes to manuscript review. Some expository studies aimed at enhancing better understanding of the subject of novelty are available and include: Gorny, (2007) and Arieti, (1976)

The clamour for objective, transparent and reliable procedures for evaluation of scientific articles has ever been on the increase, particularly to determine the impact of apublications (Adedayo, 2013; Adedayo, 2014a, b, c; Adedayo, 2015a, b, c).

In this study, attempt is made to develop a procedure to compute the novelty of manuscripts. The line of thought for this development follows from the meaning of novelty as reported in the literature.

\section{Methodology}

The framework to quantify the novelty of submitted manuscripts was developed through a systematic approach. Exposition on the meaning of novelty was made. This was used as basis to formulate mathematical expressions to quantify novelty. The categorization made by Adedayo, (2013; 2014a, b, c; 2015a, b, c) was used to classify publications cited in a new manuscript. These were used to formulate the expressions of novelty of submitted manuscript.

\subsection{What Is Novelty?}

Novelty has been explained as a quality of being new/fresh and interesting. It is a characteristics which depicts new or unusual experience or occurrence which is interesting (Gorny, 2007). It is considered that newness is not sufficient to categorize a thing as novelty; the quality of being interesting is seen as essential element. The perception of newness is context dependent, because novelty is recognized in contrast with what is considered old. Novelty depends on the difference between the perceived object and its antecedents (Gorny, 2007). Novelty is thus a function of change. The old can become the new again if it is preceded by something different; hence the phenomenon of recurrence. As a result, two levels of novelty are recognizable which are: relative and absolute novelty. These are often referred to as subjective and objective novelty respectively (Arieti, 1976). Subjective novelty is the perception of something as being new and interesting by an individual person or a group of persons; while objective novelty describes a situation where something is being seen as new for all humanity in its development through ages. It connotes the first time the thing is existing in history.

From the definition of novelty, two features standout. These features are namely: NEW and INTERESTING. New means; that which has been produced, introduced, or discovered recently or now for the first time; not existing before! It could also mean something already existing but seen, experienced, or acquired recently or now for the first time. Interesting on the other hand means: arousing curiosity or interest; holding or catching the attention. It connotes a strong desire to know or learn something. Something can be new and not interesting. Also, something may not be new but interesting. However, novelty implies newness and interesting.

\subsection{Quantification of Novelty}

Relative to the authors cited in a new manuscript, the new manuscript can be considered new because it is fresh and more current than all other cited references. Also, the level to which an article is interesting can be quantified based on the citations made within the manuscript. In the objective sense, every article cited in a new manuscript can be adjudged as interesting. The reasons are quite obvious. Firstly, the author(s) who wrote the cited references found the ideas discussed therein interesting, this is the reason the author(s) wrote on them. Also, the editor and reviewers who accepted to publish these references also found them interesting. Further still, the author of a new manuscript who cites the references in his/her manuscript also found them interesting!

Therefore, based on simple logical reasoning, all cited references are interesting. If the subject of the new manuscript expresses similar opinions as the cited references, then it should be equally interesting. However, Adedayo, $(2013 ;$ 2014a, b, c; 2015a, b, c) identified that oftentimes, not all cited references express the same opinion with the manuscript where they are cited. An example of this is seen in literature review sections when indications of opposing standpoints are made. Adedayo, (2013; 2014a, b, c; 2015a, b, c) classified the relationship of cited references to the new manuscript where they are cited as Imagined and Real. The Introduction and the Literature Review sections are classified as sections containing citations that have imagined relationship with the new manuscript, while sections including the Methodology, Results and Discussion of Results are classified as sections containing citations that have real relationship with the new manuscript.

If $\mathrm{N}_{\mathrm{I}}$ is the number of authors cited in the imaginary sections of the manuscript, and $\mathrm{N}_{\mathrm{R}}$ is the number of authors cited in the real sections of the manuscript, then an expression of the quantification of level to which the manuscript is interesting can be expressed as:

$$
M_{I}=\frac{N_{R}}{N_{I}}
$$

$M_{I}$ indicates the quantity of the level to which an article is interesting.

Similarly, a quantification of the newness of a manuscript can be made. Newness can be expressed in terms of the degree to which the new manuscript is different from existing similar publications. i.e.

$$
M_{N}=1-\frac{N_{R}}{N_{I}}
$$

Therefore, the quantity of the novelty will be directly proportional to the product of $M_{I}$ and $M_{N}$ :

$$
\text { i.e. Novelty }=v \propto M_{I} \cdot M_{N}
$$




$$
\begin{aligned}
& v \propto \frac{N_{R}}{N_{I}}\left(1-\frac{N_{R}}{N_{I}}\right) \\
& v \propto \frac{N_{R}}{N_{I}}-\left(\frac{N_{R}}{N_{I}}\right)^{2}
\end{aligned}
$$

Functional expression (5) is similar to the functional expression (6) below:

$$
f(x)=x-x^{2}
$$

By equating the derivative of function (6) to zero, i.e.:

$$
\begin{aligned}
f^{\prime}(x) & =1-2 x \\
0 & =1-2 x \\
x & =\frac{1}{2} \\
f^{\prime}(0.5) & =0.25
\end{aligned}
$$

It is clear that the maximum value of function (6) occurs at $\mathrm{x}=0.5$ and is equal to 0.25 . This is equally evident from Figure 1 which is the graph of $f(x)=x-x^{2}$

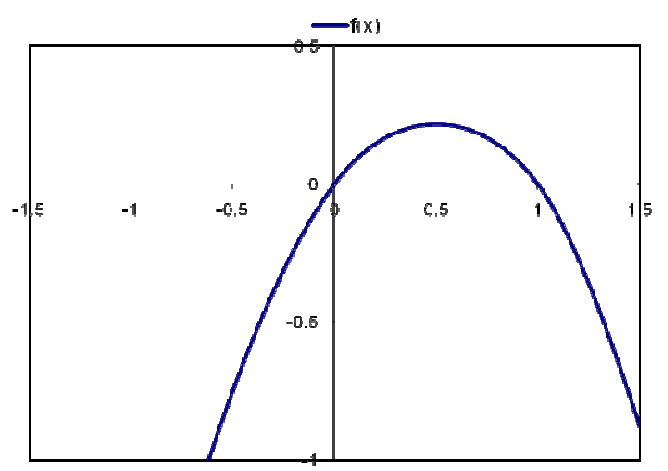

Figure 1. Graph of $f(x)=x-x^{2}$ with maximum value of 0.25 at $x=0.5$

However, Figure 1 can be modified to have a maximum of 1.0 at $\mathrm{x}=0.5$ by multiplying $\mathrm{f}(\mathrm{x})$ with a factor of 4.0 . The graph obtained is shown in Figure 2, where the maximum is 1.0 .

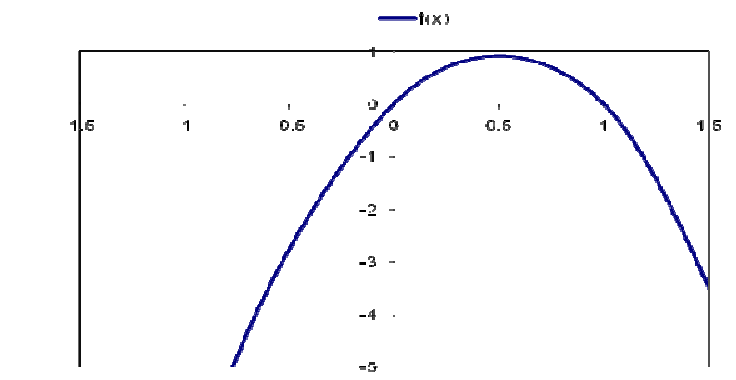

Figure 2. Graph of $f(x)=4\left(x-x^{2}\right)$ with a maximum of 1.0 at $x=0.5$

Therefore, if the maximum value of novelty must be unity (1.0), then the quantification of novelty can be written as thus:

$$
v=4\left(\frac{N_{R}}{N_{I}}-\left(\frac{N_{R}}{N_{I}}\right)^{2}\right)
$$

\section{Conclusion}

A framework to quantify the novelty of a submitted manuscript has been developed. The framework is considered to be an objective methodology to quantify the novelty of a submitted manuscript. The developed method is more useful in objective decision of the novelty of submitted manuscripts as opposed to the current frustrating subjective methodology adopted by editors and reviewers all over the world.

\section{References}

[1] Sciencedomain 2015 General Guidelines for Peer Review Process: Available

$\mathrm{http} / / /$ www.sciencedomain.org/page.php?id=sdi-generaleditorial-policy\#Peer-Review-Guideline (Accessed on: 6th May, 2015)

[2] Benos ,D.J.; Bashari „E.; Chaves, J.M. , Gaggar, A.; Kapoor, N.; LaFrance ,M.; Mans , R.; Mayhew ,D.; McGowan ,S. ; Polter ,A.; Qadri , Y.; Sarfare ,S.; Schultz ,K.; Splittgerber ,R.; Stephenson ,J.; Tower ,C.; Walton ,R.G.; Zotov, A. 2007 The ups and downs of peer review; Advances in Physiology Education Published; Vol. 31; No. 2, pp. 145-152 DOI: 10.1152/advan.00104.2006

[3] Brown T. 2006 Sense About Science. Peer Review and the Acceptance of New Scientific Ideas (online). http://www.senseaboutscience.org.uk/pdf/PeerReview.pdf

[4] Armstrong, J.S. 1997 Peer review for journals: Evidence on quality control, fairness, and innovation Science and Engineering Ethics; Vol. 3, No. 1; pp 63-84

[5] van Rooyen,S.; Godlee, F.; Evans, S. ; Smith, R.; Black, N. 1998 Effect of Blinding and Unmasking on the Quality of Peer Review: A Randomized Trial; The Journal of the American Medical Association, Vol. 280, No. 3; pp234237.doi:10.1001/jama.280.3.234.

[6] Schroter S.; Tite, L.; Hutchings, A.; Black, N. 2006; Differences in Review Quality and Recommendations for Publication Between Peer Reviewers Suggested by Authors or by Editors; The Journal of the American Medical Association; Vol. 295, No 3; pp314-317. doi:10.1001/jama.295.3.314.

[7] Fisher, M.; Friedman, S.B.; Strauss, B. 1994 The Effects of Blinding on Acceptance of Research Papers by Peer Review; The Journal of the American Medical Association, Vol. 272; No. 2, pp143-146. doi:10.1001/jama.1994.03520020069019

[8] Lee, C.J.; Sugimoto, C.R.; Zhang, G.; Cronin, B. 2012 Bias in peer review; Advances in Information Science; DOI: 10.1002/asi.22784

[9] Jefferson, T; Rudin, M ; Folse, S.B.; Davidoff, F. 2006 Editorial peer review for improving the quality of reports of biomedical studies; Cochrane Methodology Review Group DOI: 10.1002/14651858.MR000016.pub2 
[10] Gorny, E. 2007, Novelty and Originality, Available at: http://creativity.netslova.ru/Novelty_and_originality.html (Accessed on: 6th May, 2015)

[11] Arieti, S. 1976. Creativity: the magic synthesis. New York: Basic Books.

[12] Adedayo, A.V; 2013 Downsides of Impact Factor as a Valid Criterion of Quality Publications, Poster presented at the 5th Qualitative and Quantitative Methods in Libraries International Conference, 4 - 7 June, 2013; "La Sapienza" University, Rome Italy

[13] Adedayo, A.V., 2014a Downsides of Impact Factor as a Valid Criterion of Quality Publications, Elixir International Journal of Library and Information Science, 67, pp. 21918 - 21920,

[14] Adedayo, A.V. 2014b Proper Psychology for Performance of Publications, Research Journal in Organizational Psychology and Educational Studies, Vol. 3, No 4, pp. 327-329
[15] Adedayo, V; 2014c Analogies between Football and Impact Factor in Academic Publishing, Available at:http://www.thesatirist.com/essays/Impact Factor Academi c_Citations_Football.html (Accessed on: 6th May, 2015)

[16] Adedayo, A V; 2015a Pricing de Solla Price's Circumvent, Advances in Research, Available at: http://www.sciencedomain.org/abstract.php?iid=757\&id=31\& aid=7079 (Accessed on: 6th May, 2015)

[17] Adedayo, A.V 2015b Normalized Impact Factor, Elixir International Journal of Library Science, Vol. 80, pp. 3086030862

[18] Adedayo, A V 2015c Framework for Deciding Effective Impact of Publications, Journal of Scientific Research and Reports, Vol. 8; No. 1, pp. 1- 4 